Article

\title{
Correlation of Mechanical and Electrical Behavior of Polyethylene Oxide-Based Solid Electrolytes for All-Solid State Lithium-Ion Batteries
}

\author{
Fabian Peters $\mathbb{D}$, Frederieke Langer *, Nikolai Hillen, Katharina Koschek, Ingo Bardenhagen, \\ Julian Schwenzel and Matthias Busse \\ Fraunhofer-Institute for Manufacturing Technology and Advanced Materials IFAM, Wiener Str. 12, \\ 28359 Bremen, Germany; peters.fabian@freenet.de (F.P.); nikolai.hillen@gmail.com (N.H.); \\ katharina.koschek@ifam.fraunhofer.de (K.K.); ingo.bardenhagen@ifam.fraunhofer.de (I.B.); \\ julian.schwenzel@ifam.fraunhofer.de (J.S.); matthias.busse@ifam.fraunhofer.de (M.B.) \\ * Correspondence: frederieke.langer@ifam.fraunhofer.de
}

Received: 29 December 2018; Accepted: 18 February 2019; Published: 24 February 2019

\begin{abstract}
Mechanical and electrochemical stability are key issues for large-scale production of solid state Li-ion batteries. Polymer electrolytes can provide good ionic conductivity, but mechanical strength needs to be improved. In this study, we investigate the correlation of mechanical and electrical properties of poly (ethylene oxide) (PEO)-based solid electrolytes for Li-ion batteries. The influence of alumina and $\mathrm{LiClO}_{4}$ addition are investigated. Differential scanning calorimetry (DSC) is used to study the thermal behavior of salt-free and salt-containing samples and to identify the melting temperature. Dynamic mechanical analysis reveals the elastic properties as a function of temperature. Electrochemical properties are investigated using impedance spectroscopy. It is found that addition of alumina increases mechanical strength, while $\mathrm{LiClO}_{4}$ decreases it. Addition of $\mathrm{LiClO}_{4}$ and $\mathrm{Al}_{2} \mathrm{O}_{3}$ increases ionic conductivity and improves mechanical properties. However, there is no overlapping window of high mechanical strength and high ionic conductivity.
\end{abstract}

Keywords: all-solid state batteries; all-solid state electrolytes; poly (ethylene oxide) (PEO); dynamic mechanical analysis (DMA); mechanical characterization

\section{Introduction}

Development of more efficient energy storage devices is a key challenge of our time. Digitalization and miniaturization of electronic devices, as well as transformation of mobility toward electric concepts, have significant impact on our societies. Today, limited energy storage capabilities inhibit further advances in many fields, such as mobile communication and electric mobility. Future batteries need to be compact, safe, environmentally benign, and cost-efficient.

Current Li-ion technology is still making steady progress. There are constraints, however, due to the materials currently in use. Novel materials, such as high voltage cathode materials or lithium-metal anodes, require advanced electrolyte materials in order to function in a proper and safe way.

All-solid state batteries (ASSBs) are one promising candidate for the next-generation technology due to their high energy density, increased safety, and the possibility to use alternative electrode materials, such as metallic $\mathrm{Li}$, as an anode material and cobalt-free high voltage spinels as cathode materials [1].

A multitude of materials has been introduced as viable ion-conducting solid state materials for ASSBs: oxide-based ceramics (most prominently, $\mathrm{Li}_{1.3} \mathrm{Al}_{0.3} \mathrm{Ti}_{1.7}\left(\mathrm{PO}_{4}\right)_{3}[2,3]$ and $\mathrm{Li}_{7} \mathrm{La}_{3} \mathrm{Zr}_{2} \mathrm{O}_{12}[4,5]$ ), sulfides [6,7], glasses (i.e., lithium phosphorus oxynitride (LiPON) [8]), and polymers [9,10]. Oxides have been reported to be chemically stable when exposed to the environment [4], which is a clear 
safety improvement compared to liquid electrolytes. However, production of larger area battery components is challenging due to the brittle nature of these materials. Sulfides have shown very high ionic conductivities in the laboratory $[6,11]$, but have recently been reported as instable in contact with Li metal anodes [12,13]. Furthermore, sufficient wetting of the Li anode and the growth of Li dendrites during cycling are also issues for both oxides [14] and sulfides [15]. However, efforts to improve the wettability of $\mathrm{Li}$ metal, especially on $\mathrm{Li}_{7} \mathrm{La}_{3} \mathrm{Zr}_{2} \mathrm{O}_{12}$, have been successfully made [16]. LiPON is an established material for thin film batteries [8], but low ionic conductivity makes thin film processes—such as sputtering-necessary which, in turn, makes application in bulk batteries unfeasible.

Polymer electrolytes, on the other hand, promise good wetting behavior and production can easily be scaled up. Attaining high ionic conductivity at room temperature has been achieved for various systems [17-19].

Still, the most prominent polymer electrolytes are based on poly(ethylene oxide) (PEO). Ionic conduction is typically achieved by dissolving Li salts in a PEO matrix [9]. However, below the temperature of melting of PEO $\left(\sim 60^{\circ} \mathrm{C}\right)$, PEO is known to partially crystallize, which in turn, impedes ion movement within the lattice [20]. Above transition temperature of $60^{\circ} \mathrm{C}$, the structure becomes more flexible and $\mathrm{Li}^{+}$transport is accelerated. This usually leads to an improvement in specific $\mathrm{Li}^{+}$ conductivity in the range of one order of magnitude compared to temperatures below transition temperature [21,22]. Unfortunately, at the same time, the mechanical strength decreases significantly.

The addition of ceramic particles, either inert [21] or Li-ion conductive [23], has been widely investigated with the aim of improving both electrochemical and mechanical properties. While the effects of various $\mathrm{Li}$ salts and temperature ranges on the electrochemical properties of PEO are well-described in numerous studies [20,21,24-28], there are only comparatively few studies that address the impact on the mechanical properties of the solid electrolyte [29-31].

The approach presented in this study is to introduce additional, inert ceramic particles into the solid electrolyte layer in order to increase mechanical strength. The addition of such particles has been investigated in the context of achieving higher ionic conductivity by using submicron-sized particles $[28,32,33]$, neglecting the influence on the mechanical stability. In this study, larger particles $(\sim 5 \mu \mathrm{m})$ were used in order to achieve maximum mechanical stability without negatively influencing ionic transport in the polymer electrolyte. Electrochemical and mechanical methods were applied with the aim to gain a deeper understanding of how mechanical strength and ionic conductivity correlate.

\section{Results and Discussion}

In total, 10 different compositions, 5 without Li salt and 5 with Li salt, were produced (see Table 1). The samples without $\mathrm{Li}$ salt are labeled $\mathrm{PEO}$, and the following number is the weight percent of $\mathrm{Al}_{2} \mathrm{O}_{3}$ addition. The polymer sample with $\mathrm{LiClO}_{4}$ is a solid polymer electrolyte (abbreviated as SPE), while samples containing both $\mathrm{LiClO}_{4}$ and $\mathrm{Al}_{2} \mathrm{O}_{3}$ are composite polymer electrolytes (abbreviated CPE), with the number indicating the $\mathrm{Al}_{2} \mathrm{O}_{3}$ content in $w \mathrm{t} \%$.

Table 1. Composition of polymer and solid composite electrolyte samples used in this study.

\begin{tabular}{cccccc}
\hline w/o $\mathrm{LiClO}_{4}$ & PEO & PEO-5 & PEO-10 & PEO-15 & PEO-20 \\
\hline $\mathrm{PEO} / \mathrm{wt} \%$ & 100 & 95 & 90 & 85 & 80 \\
$\mathrm{Al}_{2} \mathrm{O}_{3} / \mathrm{wt} \%$ & 0 & 5 & 10 & 15 & 20 \\
\hline $\mathbf{w ~ L i C l O}$ & $\mathbf{6 P E}$ & $\mathbf{C P E}-5$ & $\mathbf{C P E}-10$ & $\mathbf{C P E - 1 5}$ & $\mathbf{C P E - 2 0}$ \\
\hline $\mathrm{PEO} / \mathrm{wt} \%$ & 87 & 82.5 & 78.2 & 73.9 & 69.5 \\
$\mathrm{LiClO}_{4} / \mathrm{wt} \%$ & 13 & 12.5 & 11.8 & 11.1 & 10.5 \\
$\mathrm{Al}_{2} \mathrm{O}_{3} / \mathrm{wt} \%$ & 0 & 5 & 10 & 15 & 20 \\
\hline
\end{tabular}




\subsection{Influence of Li Salt and Alumina on PEO Thermal Properties}

The thermal behavior of chosen samples was investigated with respect to melting events and degree of crystallinity using DSC. In Figure 1, the heat flow of the second heating cycle of composite electrolyte (CPE) and PEO samples with $0 \mathrm{wt} \%, 10 \mathrm{wt} \%$, and $15 \mathrm{wt} \% \mathrm{Al}_{2} \mathrm{O}_{3}$ is depicted.

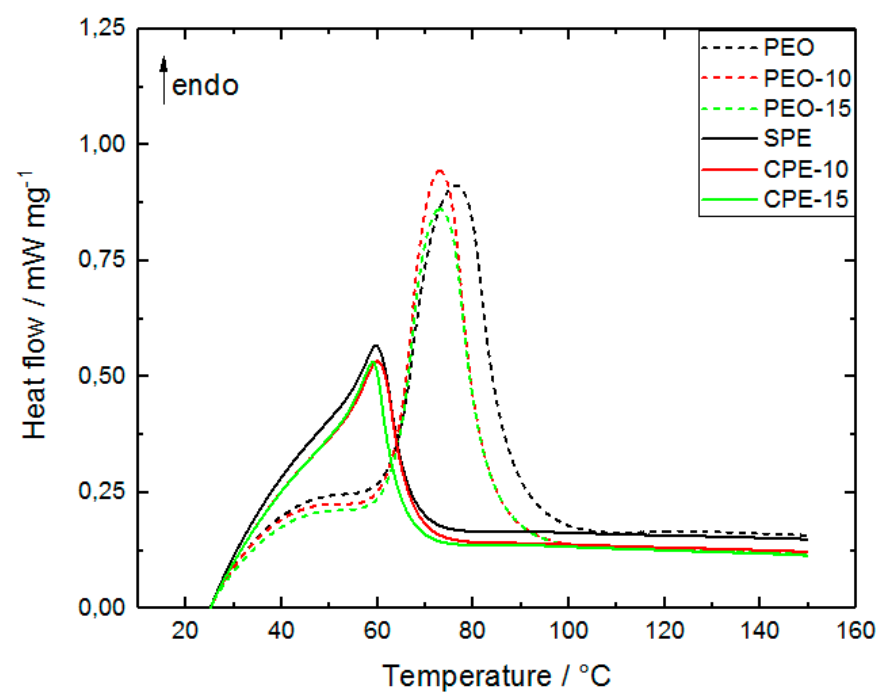

Figure 1. Second DSC heating scan of PEO and CPE samples.

For pure PEO without any additions (black dotted line), one broad endothermic peak can be observed in the investigated temperature range. The peak indicates the melting of the partially crystalline PEO with the peak maximum at $\mathrm{T}_{\mathrm{m}}=76^{\circ} \mathrm{C}$. The addition of alumina particles to the polymer only leads to marginal shift of the DSC signal to lower temperatures with $\mathrm{T}_{\mathrm{m}}=73^{\circ} \mathrm{C}$. The shape of the peak, however, becomes narrower, indicating a reduced crystallinity, which is proportional to the area below the peak. Ceramic particles are known to inhibit the arrangement of polymer chains and, therefore, crystallization, leading to a higher amorphous content in the samples. Indeed, the calculated degree of crystallinity decreases linearly with increasing alumina content. The degree of crystallinity has been determined from the peak area and is listed in Table 2.

Table 2. Determined melt enthalpy and calculated crystallinity of selected samples.

\begin{tabular}{cccc}
\hline w/o $\mathrm{LiClO}_{\mathbf{4}}$ & PEO & PEO-10 & PEO-15 \\
\hline Melting temp. $\mathrm{T}_{\mathrm{m}} /{ }^{\circ} \mathrm{C}$ & 76 & 73 & 73 \\
Enthalpy $\Delta H_{\mathrm{m}, \mathrm{N}} / \mathrm{J} \mathrm{g}^{-1}$ & 143 & 113 & 99 \\
Crystallinity $X_{\mathrm{c}, \mathrm{N}} / \%$ & 73 & 57 & 50 \\
\hline w LiClO & & CPE-10 & CPE-15 \\
\hline Melting temp. $\mathrm{T}_{\mathrm{m}} /{ }^{\circ} \mathrm{C}$ & 60 & 60 & 60 \\
Enthalpy $\Delta H_{\mathrm{m}, \mathrm{N}} / \mathrm{J} \mathrm{g}{ }^{-1}$ & 70 & 53 & 39 \\
Crystallinity $X_{\mathrm{c}, \mathrm{N}} / \%$ & 36 & 27 & 20 \\
\hline
\end{tabular}

The enthalpy of melting of a theoretically 100\% crystalline PEO sample was taken as $\Delta \mathrm{H}_{\mathrm{m}, \mathrm{calc}}=196.4 \mathrm{~J} / \mathrm{g}$ [34], and compared to the enthalpy values calculated from the DSC curves.

$$
\mathrm{X}_{\mathrm{c}, \mathrm{N}}=\left(\omega_{\mathrm{PEO}} \Delta \mathrm{H}_{\mathrm{m}, \mathrm{N}} / \Delta \mathrm{H}_{\mathrm{m}, \mathrm{calc}}\right)
$$

$\omega_{\mathrm{PEO}}$ is the mass fraction of $\mathrm{PEO}$ within the respective sample since it is assumed that $\mathrm{LiClO}_{4}$ and $\mathrm{Al}_{2} \mathrm{O}_{3}$ only contribute to a minor degree within the investigated temperature range. 
According to Equation (1), the crystallinity of the pure PEO used in this study was determined to be $73 \%$. Addition of alumina lowered the PEO's crystallinity to $50-57 \%$. Overall, however, the changes in thermal behavior due to alumina addition are only minor compared to the addition of $\mathrm{LiClO}_{4}$.

On the other hand, the presence of the $\mathrm{Li}_{\text {salt }} \mathrm{LiClO}_{4}$ affects the thermal behavior significantly. Comparing the DSC graph of the solid polymer electrolyte (SPE) sample (black solid line) with the PEO sample (black dotted line), both showed an endothermic peak. The addition of $\mathrm{LiClO}_{4}$, however, causes the peak shift to lower temperatures $\left(\mathrm{T}_{\mathrm{m}}=60^{\circ} \mathrm{C}\right)$, combined with a decrease in peak intensity. That lowers the melting temperature has been reported for $\mathrm{PEO}_{16} \mathrm{LiClO}_{4}$ electrolytes before $[20,35]$ and is attributed to the complex formation between the Li cation and the polymer chain. The calculated crystallinity decreases to $36 \%, 27 \%$, and $20 \%$ for SPE, SPE-10, and SPE- 15 , respectively, showing a strong influence of the Li salt on PEOs crystallization. Thus, Li salt addition decreases the degree of crystallinity of SPE and the appropriate composites to half of the PEO value. Comparing the crystallinity values with respect to alumina and $\mathrm{Li}$ salt addition, $\mathrm{LiClO}_{4}$ shows a greater impact by lowering the crystallinity of PEO from $73 \%$ to $36 \%$, compared to the addition of $15 \mathrm{wt} \%$ alumina (crystallinity 50\%). Hence, the further addition of alumina to SPE to create CPEs causes a comparably small reduction in crystallinity.

\subsection{Thermomechanical Properties}

The mechanical properties as a function of temperature were determined using DMA. Representative results are depicted in Figure 2, showing the storage modulus $\mathrm{E}^{\prime}$ and the loss modulus $\mathrm{E}^{\prime \prime}$ of the samples PEO and SPE, as well as PEO-15 and CPE-15. E' is shown with solid lines, while E" is drawn in dashed lines. The storage modulus $\mathrm{E}^{\prime}$ describes elastic properties of the sample, while the loss modulus E" corresponds to dissipated energy transformed into heat.
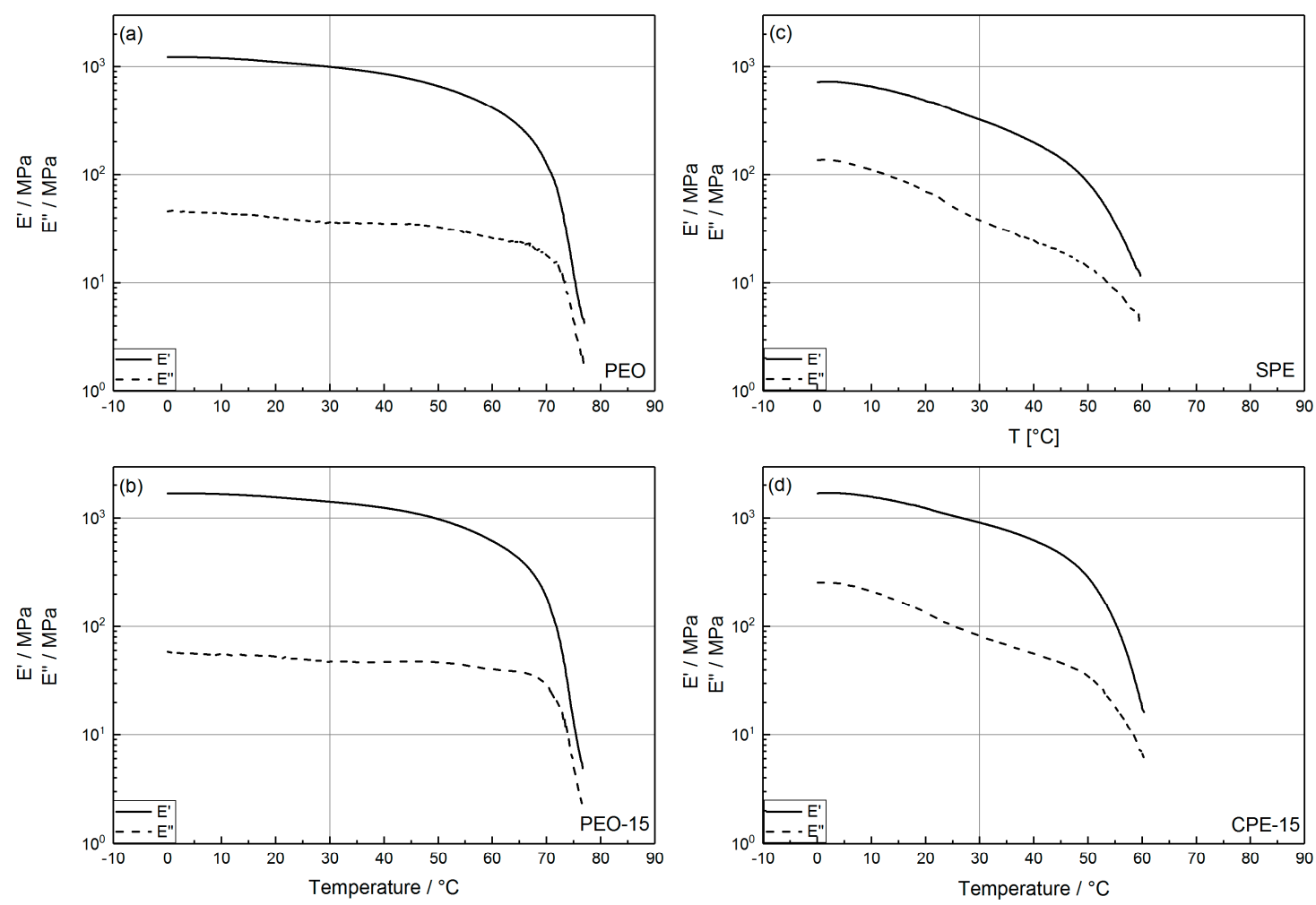

Figure 2. Storage modulus $\mathrm{E}^{\prime}$ (solid line) and loss modulus $\mathrm{E}^{\prime \prime}$ (dotted line) measured by DMA for $\mathrm{PEO}$ with and without addition of $\mathrm{LiClO}_{4}$ and $\mathrm{Al}_{2} \mathrm{O}_{3}$. (a) pure polymer PEO; (b) composite PEO-15; (c) polymer electrolyte $\mathrm{PEO}_{16} \mathrm{LiClO}_{4}(\mathrm{SPE})$; (d) composite electrolyte with $15 \mathrm{wt} \%$ alumina (CPE-15). Addition of $\mathrm{LiClO}_{4}$ shows a more distinctive effect than the addition of alumina. 
A characteristic change in $E^{\prime}$ vs. temperature is observed at distinctive temperatures. PEO shows a moderate decrease in the storage modulus $\mathrm{E}^{\prime}$ at low temperatures, above the transition temperature, however, E' decreases rapidly. This change can be attributed to the melting of PEO. Fitting the two distinctive regions with linear tangents and determining the melting point from their intersection, a value of $67^{\circ} \mathrm{C}$ is obtained. This value is slightly lower than the temperature of melting observed using DSC. Considering the lower heating rate in the DMA compared to DSC, the value obtained using DMA is expected to be lower and closer to an equilibrium melting temperature.

The addition of alumina particles increases the absolute values of $\mathrm{E}^{\prime}$, but does not change the qualitative behavior of the mechanical properties. Although the storage modulus $\mathrm{E}^{\prime}$ at low temperature (i.e., , $0{ }^{\circ} \mathrm{C}$ ) increases from 1200 to $1700 \mathrm{MPa}$ when increasing the alumina concentration from $0 \%$ to $15 \%$, the improvement is minor. Similar to the DSC results, the addition of alumina does not change the determined melting temperatures.

The addition of $\mathrm{LiClO}_{4}$ to the polymer, however, drastically changes the thermomechanical properties. Overall, the absolute values of $\mathrm{E}^{\prime}$ of SPE are decreased by addition of $\mathrm{LiClO}_{4}$ across the entire investigated temperature range. In fact, the low temperature $\mathrm{E}^{\prime}$ value of $700 \mathrm{MPa}$ for SPE is only half of the PEO value. Furthermore, $E^{\prime}$ of SPE decreases more rapidly with increasing temperature compared to $\mathrm{PEO}$ and the difference between low and high temperature in $\mathrm{E}^{\prime}$ are less pronounced in SPE.

The further addition of alumina to SPE has a more pronounced influence in $E^{\prime}$. The low temperature $\mathrm{E}^{\prime}(1690 \mathrm{MPa})$ of CPE-15 is comparable to the $\mathrm{E}^{\prime}$ of PEO-15. However, while the decrease in the storage modulus with increasing temperature is moderate below the melting point, it is more rapid at high temperatures above the melting point, compared to SPE.

At $30^{\circ} \mathrm{C}$, the storage modulus obtained for PEO is $1000 \mathrm{MPa}$. The addition of alumina increases the storage modulus with a maximum of $1415 \mathrm{MPa}$ at alumina content of $15 \mathrm{wt} \%$. By contrast, the storage modulus is only a third ( $321 \mathrm{MPa}$ ) when adding Li salt. The further addition of alumina to SPE increases the storage modulus. The initial $5 \mathrm{wt} \% \mathrm{Al}_{2} \mathrm{O}_{3}$ addition has much greater influence on the increase in storage modulus than further increasing the particle content to $20 \mathrm{wt} \%$. For all CPEs, the storage modulus $\mathrm{E}^{\prime}$ is increased to $810-950 \mathrm{MPa}$ with little variation with respect to the alumina concentration. The $\mathrm{E}^{\prime}$ values at $30^{\circ} \mathrm{C}$ obtained for all samples are summarized in Table 3.

Table 3. Storage modulus $\mathrm{E}^{\prime}$ at $30{ }^{\circ} \mathrm{C}$ determined by DMA.

\begin{tabular}{|c|c|c|c|c|c|}
\hline w/o $\mathrm{LiClO}_{4}$ & PEO & PEO-5 & PEO-10 & PEO-15 & PEO-20 \\
\hline $\mathrm{E}^{\prime} / \mathrm{MPa}$ & 1000 & 1191 & 1013 & 1415 & 1302 \\
\hline w $\mathrm{LiClO}_{4}$ & SPE & CPE-5 & CPE-10 & CPE-15 & CPE-20 \\
\hline $\mathrm{E}^{\prime} / \mathrm{MPa}$ & 321 & 881 & 809 & 910 & 948 \\
\hline
\end{tabular}

Although the loss modulus E" shows a similar temperature dependence (decrease of E" with increasing temperature), the effect of alumina and $\mathrm{LiClO}_{4}$ is quite different. PEO displays a nearly temperature-independent $\mathrm{E}^{\prime \prime}$ below the melting point and a rapid decrease in E" above the melting point. The addition of alumina to PEO (PEO-15) leads to an overall moderate increase in E", whereas the addition of $\mathrm{LiClO}_{4}$ drastically increases $\mathrm{E}^{\prime \prime}$ at low temperatures. With increasing temperature, an almost logarithmic decrease in the loss modulus is observed and the melting point cannot be determined from this graph. The further addition of alumina to SPE increases the E" values further, but does not influence the general temperature dependence of Li salt-containing samples.

There is no point of intersection between the $\mathrm{E}^{\prime}$ and $\mathrm{E}^{\prime \prime}$ graphs of any of the investigated samples. The $\mathrm{E}^{\prime}$ values are higher than the $\mathrm{E}^{\prime \prime}$ values across the entire investigated temperature range. Hence, the elastic properties dominate the thermomechanical properties of the samples and the viscoelastic properties are only minor. 
In conclusion, both the addition of $\mathrm{LiClO}_{4}$ and the addition of alumina influence the thermomechanical properties of PEO. Samples containing $\mathrm{LiClO}_{4}$ have a lower storage modulus and slightly more viscous behavior (higher loss modulus). This shows that crystallinity is reduced in $\mathrm{PEO}$ by $\mathrm{LiClO}_{4}$ addition.

Although the addition of alumina particles further decreases the crystallinity, as determined by DSC, the high stiffness of the ceramic particles can increase the stiffness (storage modulus) to values surpassing the stiffness of pure PEO. However, the decrease in melting temperature and, consequently, premature loss in mechanical stability cannot be overcome.

\subsection{EIS—Li-ion Conductivity Versus Mechanical Integrity}

For possible application as solid state electrolytes, a sufficient ionic conductivity of the CPE samples is essential. Hence, the Li-ion conductivity was determined from EIS measurements. Since the PEO samples do not contain any mobile ion species due to the lack of Li salt, only the SPE samples were determined with EIS. Figure 3 shows representative Nyquist plots of the sample SPE at various temperatures.

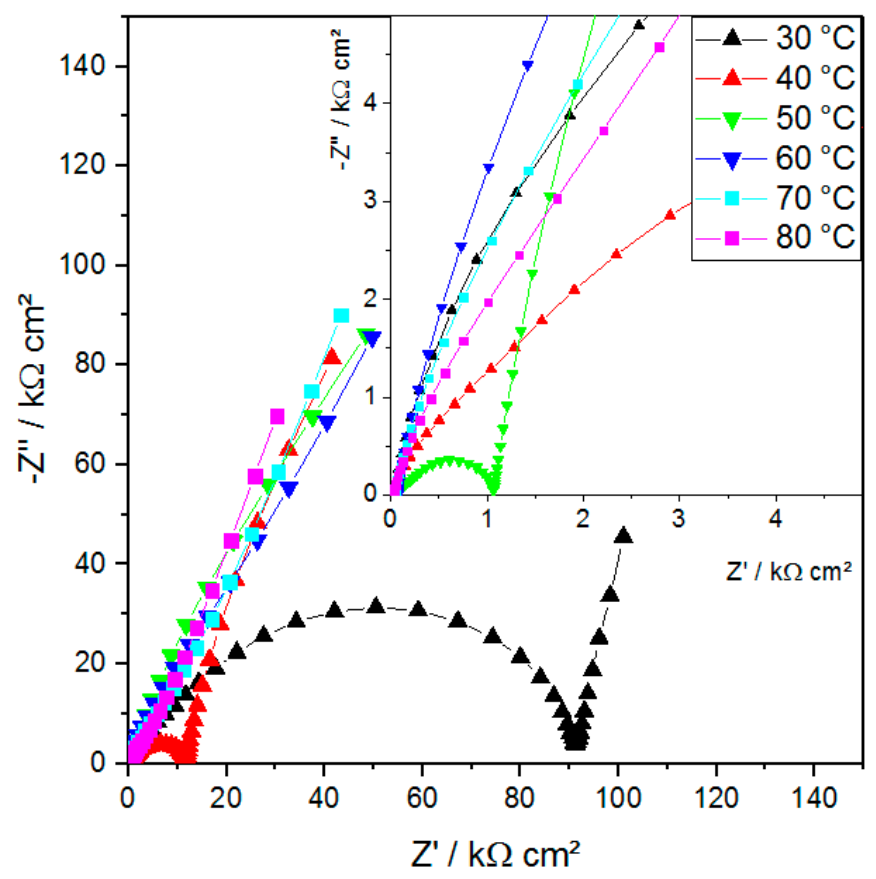

Figure 3. Nyquist plot of SPE in the range of 30 to $80^{\circ} \mathrm{C}$. Inset shows high frequency region.

At low temperatures of $30^{\circ} \mathrm{C}$, a typical depressed semicircle at high frequencies and a tail at low frequencies are observed. The high frequency semicircle is attributed to the combination of resistive and capacitive elements within the SPE, while the straight line at low frequencies is the result of the ion-blocking stainless steel electrodes. The asymmetry, or depression, of the semicircle may arise from the semicrystalline nature of the samples at low temperatures. The ionic conductivity of the amorphous phase varies from the conductivity and time constant within the crystalline phase. Depending on the volume ratio and conductivity of the phases at a given temperature, the time constants of these two different processes lead to the formation of two semicircles, which may overlap to form one depressed semicircle with an asymmetry. However, a clear separation of the semicircles and attribution to the amorphous and crystalline phases within the sample is not possible. The resistance of the sample can be determined from the low frequency end of the semicircle and is $90 \mathrm{kOhm} \mathrm{cm}{ }^{2}$ at $30^{\circ} \mathrm{C}$. With increasing temperature, the diameter of the semicircle decreases until $60{ }^{\circ} \mathrm{C}$, while it disappears above that temperature. At such high temperatures, there are only frequency-independent resistance 
and the low frequency tail to be observed. These qualitative results can be observed for all CPE samples in this study.

Ionic conductivity was calculated from the resistance (low frequency end of the semicircle at low temperatures, or the intersection of the $Z^{\prime}$-axis and the respective tails at high temperatures) and the sample geometry. In Figure 4, the calculated ionic conductivities for SPE and CPE-5 to CPE-20 are displayed as a function of temperature.

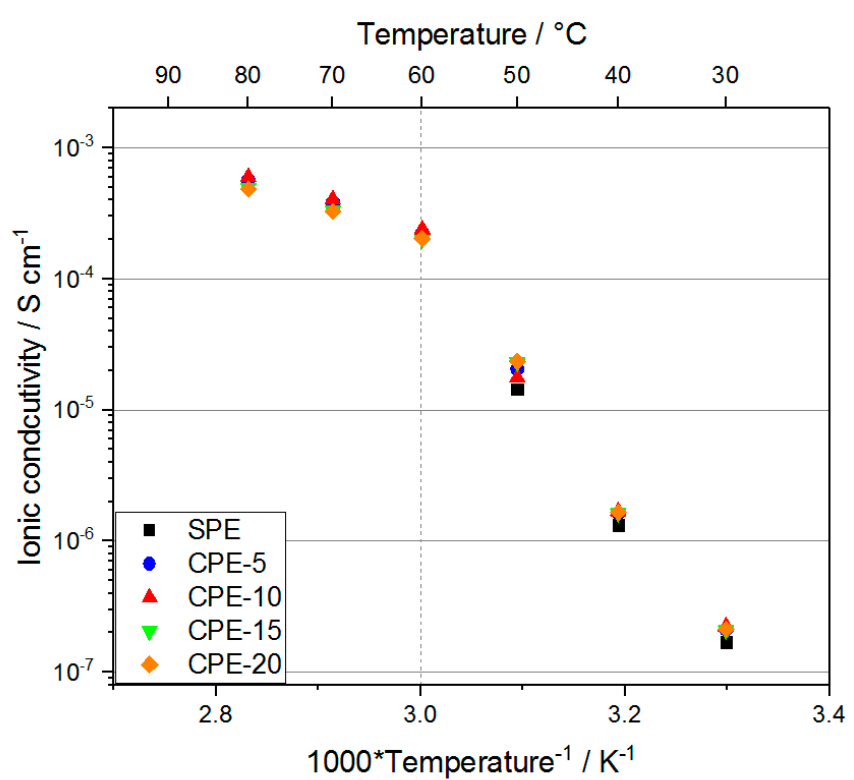

Figure 4. Ionic conductivity of CPE samples obtained from impedance data as a function of temperature.

For all samples, the conductivity increases with increasing temperature. Two regions can be distinguished. From 30 to $60{ }^{\circ} \mathrm{C}$, there is a steep increase in the conductivity from about $2 \times 10^{-7} \mathrm{~S} / \mathrm{cm}$ at $30^{\circ} \mathrm{C}$, to over almost 1000 -fold higher $\left(2 \times 10^{-4} \mathrm{~S} / \mathrm{cm}\right.$ at $\left.60{ }^{\circ} \mathrm{C}\right)$ with increasing temperature. Above $60{ }^{\circ} \mathrm{C}$, the increase is less pronounced. Ionic conductivity is increased further at elevated temperature and reaches values of approximately $5 \times 10^{-4} \mathrm{~S} / \mathrm{cm}$ at $80^{\circ} \mathrm{C}$ for all samples.

These two different regions are the result of the phase changes within the sample. At low temperatures, the polymer is solid and partially crystalline. The segmental movement of polymer chains necessary to transport the Li ions is constrained. Therefore, the ionic conductivity is low. From the DSC results, it is obvious that at $60{ }^{\circ} \mathrm{C}$ the crystalline parts of the polymer melt. Hence, at temperatures above the melting temperature, the segmental motion of polymer chains is facilitated which, in turn, results in higher ionic conductivity.

The differences in the plotted conductivities of samples with differing $\mathrm{Al}_{2} \mathrm{O}_{3}$ content are hardly distinguishable from Figure 4 . Therefore, the ionic conductivity at $30^{\circ} \mathrm{C}$ and $80{ }^{\circ} \mathrm{C}$ is plotted in Figure 5 as a function of the alumina content.

It can be seen that small concentrations of alumina up to $10 \mathrm{wt} \%$ beneficially affect the ionic conductivity since the conductivity values increase. At higher alumina concentrations, the conductivity decreases again. Nevertheless, at $30^{\circ} \mathrm{C}$, the value at $20 \mathrm{wt} \%$ is still higher than the value for SPE without alumina. At high temperatures of $80^{\circ} \mathrm{C}$, however, the conductivity value of highly filled samples drops below the conductivity of the unfilled sample. At both temperatures, this drop is probably caused by the formation of agglomerates of non-conductive filler particles. Such agglomerates are exemplarily shown in the scanning electron microscopy (SEM) image in Figure 6. It can be seen that the alumina particles (light grey) stick together and form regions of non-conductive material within the polymer electrolyte matrix (dark grey). 


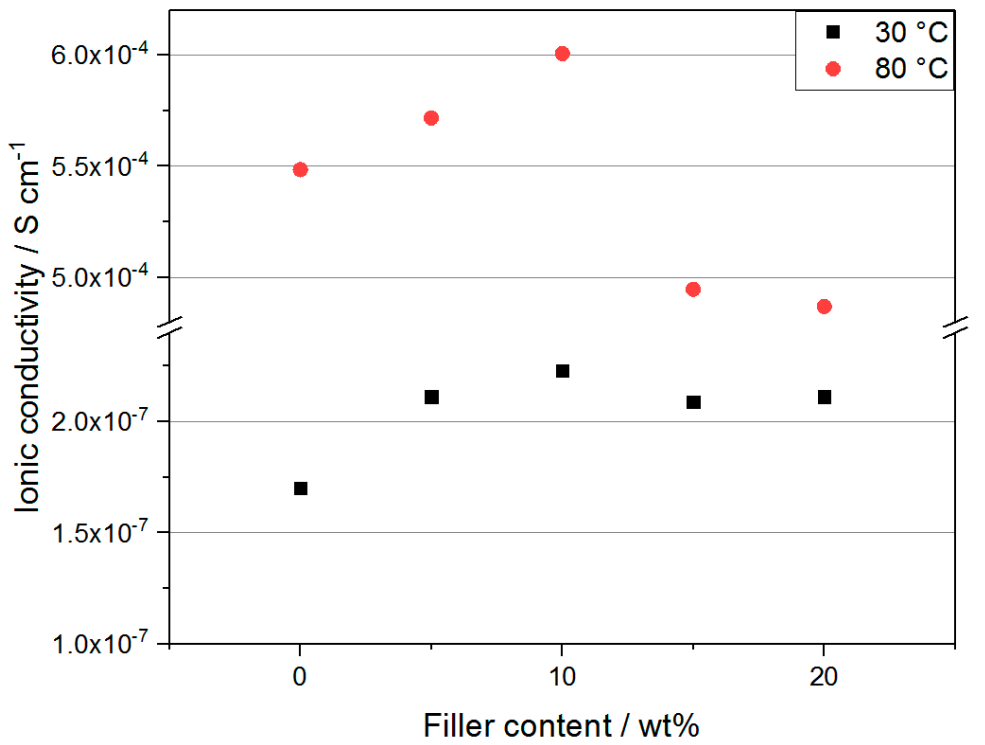

Figure 5. Ionic conductivity as a function filler content at $30^{\circ} \mathrm{C}$ (black squares) and $80{ }^{\circ} \mathrm{C}$ (red circles)

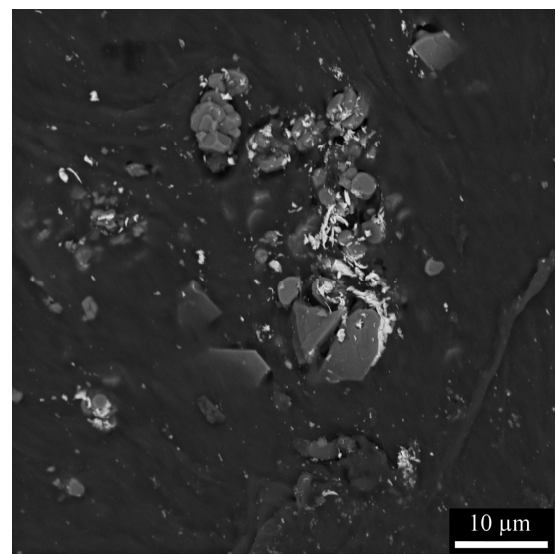

Figure 6. SEM image of alumina agglomerates forming in composite electrolytes with high filler amount.

When the amount of filler particles exceeds a certain limit, the particles are no longer homogeneously distributed and, hence, inhibit the transport of $\mathrm{Li}$ ions. This optimum amount of alumina particles within the polymer matrix for high ionic conductivity is $10 \mathrm{wt} \%$. This result is in good agreement with previous studies on ionic conductivity of ceramic-filled polymer electrolytes, which also found a maximum in conductivity for addition of $10 \mathrm{wt} \%$ filler particles [36-39]. However, previous studies often report a higher effect of particle addition to the polymer electrolyte. While here the ionic conductivity is almost doubled by the addition of $10 \mathrm{wt} \%$ alumina, other studies show an increase of about one magnitude [40]. However, it should be noted that, in these studies, the particles used have a much smaller particles size (a few $\mathrm{nm}$ ) [38] compared to the size used here (about $5 \mu \mathrm{m}$ ). Comparing the magnitude of the effect at the two different temperatures, it is notable that the drop in conductivity is much higher at $80^{\circ} \mathrm{C}$ than at $30^{\circ} \mathrm{C}$. While at $80^{\circ} \mathrm{C}$, the entire polymer electrolyte is in an amorphous state, at $30^{\circ} \mathrm{C}$, the samples are partially crystalline. It seems that at $30^{\circ} \mathrm{C}$, the remaining crystallinity impedes the ionic conductivity drastically.

For comparison of mechanical and electrical results, the storage modulus and ionic conductivity of the CPE samples are correlated in Figure 7. 


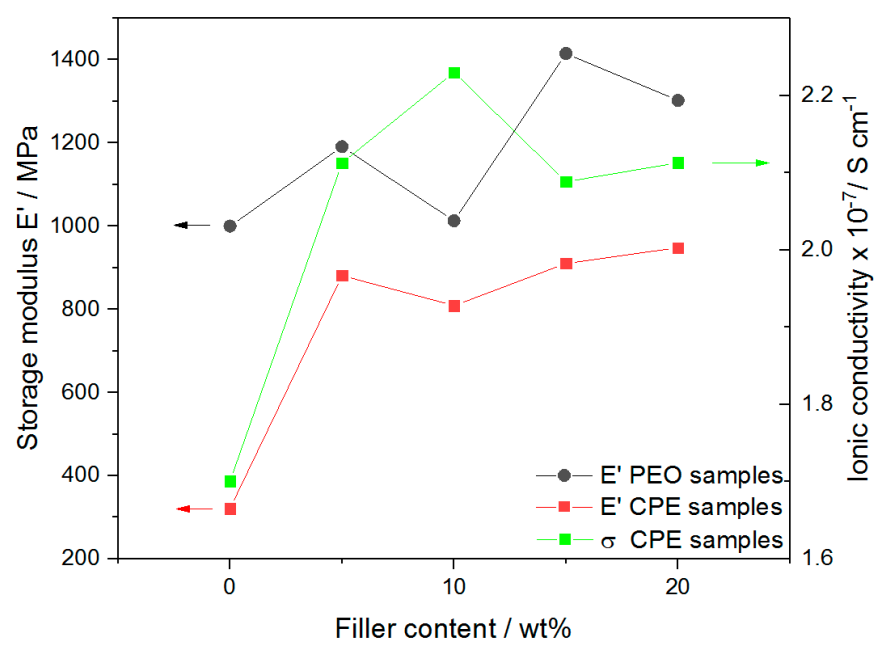

Figure 7. Comparison of storage modulus and ionic conductivity at $30^{\circ} \mathrm{C}$ as a function of alumina (filler) content.

It can be seen that the addition of small amounts ( $5 \mathrm{wt} \%$ ) of alumina particles to the SPE not only increases the ionic conductivity, but also the mechanical stability. However, while the increase in stiffness is more than twofold, the increase in ionic conductivity is far smaller. Furthermore, the addition of $10 \mathrm{wt} \%$ alumina, which results in the maximum increase in conductivity reported here, is accompanied with the lowest storage modulus of alumina-reinforced composites investigated here. Hence, while from the mechanical point of view, a higher filling degree with ceramic particles may have more positive results on the mechanical stability, the ionic conductivity will most likely suffer from the high amount of inert particles.

One further striking observation in this study is that the mechanical strength of the material drops at temperatures well below those where the ionic conductivity reaches values suitable for application $\left(>10^{-4} \mathrm{~S} / \mathrm{cm}\right)$. DMA results show that mechanical strength of CPE can only be maintained to the onset of melting ( 5 to $10^{\circ} \mathrm{C}$ below the melting temperature determined using DSC). Ionic conductivity at this point is still considerably lower than conductivity above the melting temperature.

\section{Materials and Methods}

\subsection{Preparation of Solid Electrolyte Samples}

Polymer and solid polymer electrolyte samples comprising polyethylene oxide (PEO, $M_{w}=100,000 \mathrm{~g} / \mathrm{mol}$, Alfa Aesar, Karlsruhe, Germany), lithium perchlorate $\left(\mathrm{LiClO}_{4}, 99.9 \%\right.$, battery grade, Sigma Aldrich, Munich, Germany), and varying amounts of aluminum oxide $\left(\mathrm{Al}_{2} \mathrm{O}_{3}\right.$, median particle size $5.1 \mu \mathrm{m}$, Nabaltec, Schwandorf, Germany) were prepared. All chemicals were dried in vacuum for $12 \mathrm{~h}$ and transferred into an Ar-filled glovebox (MBraun, $\mathrm{H}_{2} \mathrm{O}$ and $\mathrm{O}_{2}$ $<0.1 \mathrm{ppm}$ ) before use. All further steps were carried out inside an Ar-filled glove box to avoid any contamination with $\mathrm{H}_{2} \mathrm{O}$, which might be detrimental to material properties. First, appropriate amounts of all components were mixed in acetonitrile. A laboratory-scale magnetic stirrer was used for the dissolution of $\mathrm{PEO}$ and $\mathrm{LiClO}_{4}$ and dispersion of $\mathrm{Al}_{2} \mathrm{O}_{3}$. Stirring was continued until a homogeneous dispersion was obtained. The dispersion was cast onto a PTFE dish to a level of several millimeters, and stored inside the glove box at room temperature for at least $48 \mathrm{~h}$ to allow for evaporation of all solvent. After drying, the product was removed from the PTFE dish and extruded by a laboratory-sized extruder (HAAKE Minilab II, Thermo Scientific, Germany). The melt extrusion process was included for compacting and homogenizing of the material, as the drying process leaves behind voids previously occupied by solvent. Those voids would potentially reduce the quality of the solid electrolyte by reducing mechanical strength and hindering ion transport. Continuous 
stripes of ca. $2 \times 1 \mathrm{~mm}^{2}$ free of voids were obtained after extrusion as a semifinished product for further analysis.

Table 1 gives the composition of each sample produced for this study. In total, 10 different compositions were produced by the method described above. One composition of solid polymer electrolyte $\mathrm{PEO}_{16} \mathrm{LiClO}_{4}$ (SPE) was prepared. The ratio of $\mathrm{PEO}$ to $\mathrm{LiClO}_{4}$ was kept constant in all cases to maintain the ratio of ethylene oxide monomer units $(\mathrm{n}(\mathrm{EO}))$ and lithium ions (n(Li)) at 16:1. In addition, 4 compositions of composite polymer electrolytes (CPE-5, CPE-10, CPE-15, and CPE-20) comprising $\mathrm{PEO}_{16} \mathrm{LiClO}_{4}$ electrolyte containing different amounts of $\mathrm{Al}_{2} \mathrm{O}_{3}$ were prepared. The $\mathrm{Al}_{2} \mathrm{O}_{3}$ content varied between 0 and $20 \mathrm{wt} \%$ in steps of $5 \mathrm{wt} \%$. For reference and investigation of the effect of Li salt addition, 5 samples containing only PEO and alumina were also prepared without the Li salt and are labeled PEO, PEO-5, etc.

\subsection{Analytical Methods}

Differential scanning calorimetry (DSC, STA 449F3, Netzsch, Germany) measurements were carried out for selected samples to investigate the influence of $\mathrm{Al}_{2} \mathrm{O}_{3}$ and $\mathrm{LiClO}_{4}$ addition on the thermal properties of polymer electrolyte. Small amounts of extruded sample were heated from 25 to $150{ }^{\circ} \mathrm{C}$ at $5 \mathrm{~K} / \mathrm{min}$. Two heating/cooling cycles were carried out. The first heating/cooling run was included for sample conditioning only, and not used for material evaluation.

Temperature-dependent dynamic mechanical analysis (DMA) was used for determination of complex Young's modulus. Rectangular-shaped samples with dimensions $10 \times 18 \times 2 \mathrm{~mm}^{3}$ were produced from the extruded solid electrolyte by a custom-made forming mold. Strips of extruded samples were loaded in the cavities. After heating to $100{ }^{\circ} \mathrm{C}$ in vacuum, the die was closed with a top plate by tightening the screws at the edge of the top plate. The material was then allowed to cool down in vacuum and the resulting rectangular blocks were removed from the mold. DMA measurements were performed with a dynamic mechanical analyzer (DMA 2980, TA Instruments, New Castle, IN, USA) in single cantilever mode at $1 \mathrm{~Hz}$ and $10 \mu \mathrm{m}$ amplitude. An upwards temperature ramp of $2 \mathrm{~K} / \mathrm{min}$ was applied in the range of 0 to $80^{\circ} \mathrm{C}$. The exact sample geometry was measured and used for evaluation of each individual measurement. DMA results were obtained in the form of temperature-dependent storage modulus $\mathrm{E}^{\prime}$ and loss modulus $\mathrm{E}^{\prime \prime}$. $\mathrm{E}^{\prime}$ and $\mathrm{E}^{\prime \prime}$ stand for the elastic and the viscous portions of $\mathrm{E}$, respectively.

SEM images were taken with a Phenom ProX (Quantum LOT).

Impedance spectroscopy (EIS) was used to determine ionic conductivity of the produced solid electrolyte samples as a function of temperature. Preparation of the test cells was performed in an Ar-filled glove box. Thin solid electrolyte discs ( $150 \mu \mathrm{m}$ thick) were produced by hot pressing small amounts of the extruded material. Typically, $60-80 \mathrm{mg}$ was heated to $100{ }^{\circ} \mathrm{C}$ in vacuum and subsequently hot-pressed for at least 1 minute. After pressing, discs of $16 \mathrm{~mm}$ diameter were punched from the produced foils and placed in the center of a $150 \mu \mathrm{m}$-thick PP spacer ring (outer diameter $18 \mathrm{~mm}$, inner diameter $16 \mathrm{~mm}$ ). The ring was included to provide additional mechanical stability during testing and avoid short-circuiting of the cell. Samples were contacted by two pieces of $50 \mu \mathrm{m}$ thick stainless steel foil. The sandwich was then placed in an EL-Cell test case (ECC-STD, EL-Cell, Hamburg, Germany). A Gamry Reference 600 potentiostat (Gamry Instruments, Warminster, PA, USA) was used for EIS measurements. Measurements were performed in a frequency range of $10^{6}-10^{-1} \mathrm{~Hz}$ at $10 \mathrm{mV}$ amplitude. Prior to the first measurement, the cells were heated to $80^{\circ} \mathrm{C}$. EIS was performed with a descending temperature range from 80 to $30^{\circ} \mathrm{C}$ in $10^{\circ} \mathrm{C}$ steps. Each temperature was kept for $1 \mathrm{~h}$ before the start of the EIS measurement to allow for temperature equilibration within the test setup.

\section{Conclusions}

Mechanical and electrical properties of PEO-based composite polymer electrolytes for Li-ion batteries were investigated in this study. It is shown that both addition of $\mathrm{LiClO}_{4}$ and microparticles of alumina (ca. $5 \mu \mathrm{m}$ ) have distinctive influence. While the melting temperature is hardly influenced by 
alumina particles, DSC and DMA clearly show that the Li salt reduces the melting temperature and mechanical stiffness considerably. While addition of alumina to solid polymer electrolyte increases the mechanical stiffness, the melting temperature remains low. Analysis of the impedance spectroscopy data confirmed that the increase in ionic conductivity for $\mathrm{Li}^{+}$in the polymer is directly connected to change in material structure from semicrystalline to amorphous and melted.

DMA further reveals that the mechanical strength of the polymer samples decreased some 5 to $10 \mathrm{~K}$ below the transition temperature determined from DSC and EIS. Addition of $\mathrm{LiClO}_{4}$ increases the gap between the transition temperature determined with EIS and DMA. No overlapping window of high mechanical strength and high ionic conductivity could be found. Thus, stabilization of $\mathrm{PEO} / \mathrm{LiClO}_{4}$ electrolyte by only introducing of inert ceramic particles, with particles sizes in the micrometer up to $20 \mathrm{wt} \%$, does not seem feasible. One possible solution would be the development of hybrid structures comprising polymer solid electrolyte and a rigid superstructure. This will be subject to future studies.

Author Contributions: Conceptualization, F.P. and K.K.; investigation, N.H.; formal analysis, F.L., I.B., K.K; writing-original draft preparation, F.P. and F.L.; writing-review and editing, K.K. and F.L.; supervision, K.K., J.S. and M.B.; project administration, F.P.

Acknowledgments: The authors gratefully acknowledge Iris Gottschalk for conducting DMA measurements and Sebastian Jentzsch for preparing electrochemical test cells.

Conflicts of Interest: The authors declare no conflict of interest.

\section{References}

1. Janek, J.; Zeier, W.G. A solid future for battery development. Nat. Energy 2016, 1, 16141. [CrossRef]

2. Monchak, M.; Hupfer, T.; Senyshyn, A.; Boysen, H.; Chernyshov, D.; Hansen, T.; Schell, K.G.; Bucharsky, E.C.; Hoffmann, M.J.; Ehrenberg, H. Lithium Diffusion Pathway in Li(1.3)Al(0.3)Ti(1.7)(PO4)3 (LATP) Superionic Conductor. Inorg. Chem. 2016, 55, 2941-2945. [CrossRef] [PubMed]

3. Dashjav, E.; Tietz, F. Neutron Diffraction Analysis of NASICON-type $\mathrm{Li}_{1+\mathrm{x}} \mathrm{Al}_{\mathrm{x}} \mathrm{Ti}_{2-\mathrm{x}} \mathrm{P}_{3} \mathrm{O}_{12}$. Zeitschrift für Anorganische und Allgemeine Chemie 2014, 640, 3070-3073. [CrossRef]

4. Murugan, R.; Thangadurai, V.; Weppner, W.J.F. Schnelle Lithiumionenleitung in granatartigem $\mathrm{Li}_{7} \mathrm{La}_{3} \mathrm{Zr}_{2} \mathrm{O}_{12}$. Angew. Chem. 2007, 119, 7925-7928. [CrossRef]

5. Langer, F.; Glenneberg, J.; Bardenhagen, I.; Kun, R. Synthesis of single phase cubic Al-substituted $\mathrm{Li}_{7} \mathrm{La}_{3} \mathrm{Zr}_{2} \mathrm{O}_{12}$ by solid state lithiation of mixed hydroxides. J. Alloys Compd. 2015, 645, 64-69. [CrossRef]

6. Kato, Y.; Hori, S.; Saito, T.; Suzuki, K.; Hirayama, M.; Mitsui, A.; Yonemura, M.; Iba, H.; Kanno, R. High-power all-solid-state batteries using sulfide superionic conductors. Nat. Energy 2016, 1, 16030. [CrossRef]

7. Liu, D.; Zhu, W.; Feng, Z.; Guerfi, A.; Vijh, A.; Zaghib, K. Recent progress in sulfide-based solid electrolytes for Li-ion batteries. Mater. Sci. Eng. B 2016, 213, 169-176. [CrossRef]

8. Glenneberg, J.; Andre, F.; Bardenhagen, I.; Langer, F.; Schwenzel, J.; Kun, R. A concept for direct deposition of thin film batteries on flexible polymer substrate. J. Power Sources 2016, 324, 722-728. [CrossRef]

9. Armand, M.B. Polymers with Ionic Conductivity. Adv. Mater. 1990, 2, 278-286. [CrossRef]

10. Xue, Z.; He, D.; Xie, X. Poly(ethylene oxide)-based electrolytes for lithium-ion batteries. J. Mater. Chem. A 2015, 3, 19218-19253. [CrossRef]

11. Bron, P.; Johansson, S.; Zick, K.; Schmedt auf der Günne, J.; Dehnen, S.; Roling, B. $\mathrm{Li}_{10} \mathrm{SnP}_{2} \mathrm{~S}_{12}$ : An affordable lithium superionic conductor. J. Am. Ceram. Soc. 2013, 135, 15694-15697. [CrossRef] [PubMed]

12. Wenzel, S.; Weber, D.A.; Leichtweiss, T.; Busche, M.R.; Sann, J.; Janek, J. Interphase formation and degradation of charge transfer kinetics between a lithium metal anode and highly crystalline $\mathrm{Li}_{7} \mathrm{P}_{3} \mathrm{~S}_{11}$ solid electrolyte. Solid State Ion. 2016, 286, 24-33. [CrossRef]

13. Wenzel, S.; Randau, S.; Leichtweiß, T.; Weber, D.A.; Sann, J.; Zeier, W.G.; Janek, J. Direct Observation of the Interfacial Instability of the Fast Ionic Conductor $\mathrm{Li}_{10} \mathrm{GeP}_{2} \mathrm{~S}_{12}$ at the Lithium Metal Anode. Chem. Mater. 2016, 28, 2400-2407. [CrossRef]

14. Cheng, E.J.; Sharafi, A.; Sakamoto, J. Intergranular Li metal propagation through polycrystalline $\mathrm{Li}_{6.25} \mathrm{Al}_{0.25} \mathrm{La}_{3} \mathrm{Zr}_{2} \mathrm{O}_{12}$ ceramic electrolyte. Electrochim. Acta 2017, 223, 85-91. [CrossRef] 
15. Porz, L.; Swamy, T.; Sheldon, B.W.; Rettenwander, D.; Frömling, T.; Thaman, H.L.; Berendts, S.; Uecker, R.; Carter, W.C.; Chiang, Y.-M. Mechanism of Lithium Metal Penetration through Inorganic Solid Electrolytes. Adv. Energy Mater. 2017, 414, 1701003. [CrossRef]

16. Tsai, C.-L.; Roddatis, V.; Chandran, C.V.; Ma, Q.; Uhlenbruck, S.; Bram, M.; Heitjans, P.; Guillon, O. $\mathrm{Li}_{7} \mathrm{La}_{3} \mathrm{Zr}_{2} \mathrm{O}_{12}$ Interface Modification for Li Dendrite Prevention. ACS Appl. Mater. Interfaces 2016, 8, 10617-10626. [CrossRef] [PubMed]

17. Mindemark, J.; Sun, B.; Törmä, E.; Brandell, D. High-performance solid polymer electrolytes for lithium batteries operational at ambient temperature. J. Power Sources 2015, 298, 166-170. [CrossRef]

18. Zuo, X.; Liu, X.-M.; Cai, F.; Yang, H.; Shen, X.-D.; Liu, G. A novel all-solid electrolyte based on a co-polymer of poly-(methoxy/hexadecal-poly(ethylene glycol) methacrylate) for lithium-ion cell. J. Mater. Chem. 2012, 22, 22265-22271. [CrossRef]

19. Wang, H.; Matsui, M.; Takeda, Y.; Yamamoto, O.; Im, D.; Lee, D.; Imanishi, N. Interface Properties between Lithium Metal and a Composite Polymer Electrolyte of PEO18Li(CF3SO2)2N-Tetraethylene Glycol Dimethyl Ether. Membranes 2013, 3, 298-310. [CrossRef] [PubMed]

20. Choi, B.-K.; Kim, Y.-W. Conductivity relaxation in the PEO-salt polymer electrolytes. Electrochim. Acta 2004, 49, 2307-2313. [CrossRef]

21. Croce, F.; Scrosati, B. Nanocomposite Lithium Ion Conducting Membranes. Ann. N. Y. Acad. Sci. 2003, 984, 194-207. [CrossRef] [PubMed]

22. Fergus, J.W. Ceramic and polymeric solid electrolytes for lithium-ion batteries. J. Power Sources 2010, 195, 4554-4569. [CrossRef]

23. Langer, F.; Bardenhagen, I.; Glenneberg, J.; Kun, R. Microstructure and temperature dependent lithium ion transport of ceramic-polymer composite electrolyte for solid-state lithium ion batteries based on garnet-type $\mathrm{Li}_{7} \mathrm{La}_{3} \mathrm{Zr}_{2} \mathrm{O}_{12}$. Solid State Ion. 2016, 291, 8-13. [CrossRef]

24. Agrawal, R.C.; Pandey, G.P. Solid polymer electrolytes: Materials designing and all-solid-state battery applications: An overview. J. Phys. D Appl. Phys. 2008, 41, 223001. [CrossRef]

25. Nunes-Pereira, J.; Costa, C.M.; Lanceros-Méndez, S. Polymer composites and blends for battery separators: State of the art, challenges and future trends. J. Power Sources 2015, 281, 378-398. [CrossRef]

26. Wetjen, M.; Kim, G.-T.; Joost, M.; Winter, M.; Passerini, S. Temperature dependence of electrochemical properties of cross-linked poly(ethylene oxide)-lithium bis(trifluoromethanesulfonyl)imide-N-butyl-Nmethylpyrrolidinium bis(trifluoromethanesulfonyl)imide solid polymer electrolytes for lithium batteries. Electrochim. Acta 2013, 87, 779-787. [CrossRef]

27. Appetecchi, G.B.; Carewska, M.; Alessandrini, F.; Prosini, P.P.; Passerini, S. Characterization of PEO-Based Composite Cathodes. I. Morphological, Thermal, Mechanical, and Electrical Properties. J. Electrochem. Soc. 2000, 147, 451-459. [CrossRef]

28. Croce, F.; Persi, L.; Ronci, F.; Scrosati, B. Nanocomposite polymer electrolytes and their impact on the lithium battery technology. Solid State Ion. 2000, 135, 47-52. [CrossRef]

29. Maitra, M.; Sinha, M.; Mukhopadhyay, A.; Middya, T.; De, U.; Tarafdar, S. Ion-conductivity and Young's modulus of the polymer electrolyte PEO-ammonium perchlorate. Solid State Ion. 2007, 178, 167-171. [CrossRef]

30. Ogata, N.; Kawakage, S.; Ogihara, T. Structure and thermal/mechanical properties of poly(ethylene oxide)-clay mineral blends. Polymer 1997, 38, 5115-5118. [CrossRef]

31. Safdari, F.; Carreau, P.J.; Heuzey, M.C.; Kamal, M.R.; Sain, M.M. Enhanced properties of poly(ethylene oxide)/cellulose nanofiber biocomposites. Cellulose 2017, 24, 755-767. [CrossRef]

32. Croce, F.; Appetecchi, G.B.; Persi, L.; Scrosati, B. Nanocomposite polymer electrolytes for lithium batteries. Nature 1998, 394, 456-458. [CrossRef]

33. Wang, W.; Alexandridis, P. Composite Polymer Electrolytes: Nanoparticles Affect Structure and Properties. Polymers 2016, 8, 387. [CrossRef]

34. Wunderlich, B. (Ed.) Macormolecular Physics; Academic Press: New York, NY, USA, 1980.

35. Malathi, M.; Tamilarasan, K.; Ganesan, V. Role of ceramic reinforcement in composite polymer electrolyte. Polym. Compos. 2015, 36, 42-46. [CrossRef]

36. Weston, J.; Steele, B. Effects of inert fillers on the mechanical and electrochemical properties of lithium salt-poly(ethylene oxide) polymer electrolytes. Solid State Ion. 1982, 7, 75-79. [CrossRef] 
37. Scrosati, B.; Croce, F. Composite polymer ionics: Advanced electrolyte materials for thin-film batteries. Polym. Adv. Technol. 1993, 4, 198-204. [CrossRef]

38. Capiglia, C.; Yang, J.; Imanishi, N.; Hirano, A.; Takeda, Y.; Yamamoto, O. Composite polymer electrolyte: The role of filler grain size. Solid State Ion. 2002, 154-155, 7-14. [CrossRef]

39. Chen, L.; Li, Y.; Li, S.-P.; Fan, L.-Z.; Nan, C.-W.; Goodenough, J.B. PEO/garnet composite electrolytes for solid-state lithium batteries: From "ceramic-in-polymer" to "polymer-in-ceramic". Nano Energy 2018, 46, 176-184. [CrossRef]

40. Appetecchi, G.B.; Croce, F.; Persi, L.; Ronci, F.; Scrosati, B. Transport and interfacial properties of composite polymer electrolytes. Electrochim. Acta 2000, 45, 1481-1490. [CrossRef]

(C) 2019 by the authors. Licensee MDPI, Basel, Switzerland. This article is an open access article distributed under the terms and conditions of the Creative Commons Attribution (CC BY) license (http://creativecommons.org/licenses/by/4.0/). 